\title{
Comparative analysis of medical images watermarking methods
}

\section{Analiza porównawcza metod znakowania wodnego obrazów medycznych}

\author{
Sylwia Duda*, Dominik Fijałek*, Grzegorz Kozieł \\ Department of Computer Science, Lublin University of Technology, Nadbystrzycka 36B, 20-618 Lublin, Poland
}

\begin{abstract}
The article is devoted to the analysis of watermarking algorithms in terms of their use in marking medical images. The algorithms based on the Integer Wavelet Transform (IWT), Discrete Cosine Transform (DCT), and Singular Value Decomposition (SVD) were compared. The algorithms were implemented using the combinations: IWT, IWT-DCT, and IWT-SVD. As part of the research, the level of disturbances caused by embedding the watermark was checked using subjective and objective methods. The attack resistance of the watermarked images was tested and the steganographic capacity was measured. All algorithms are based on IWT, however, each has different advantages. The algorithm based on the IWT showed the highest capacity. The most resistant to attacks is IWT-SVD, and the lowest level of interference was obtained for the IWT-DCT algorithm.
\end{abstract}

Keywords: watermarking; IWT; DCT; SVD

\section{Streszczenie}

Artykuł poświęcono analizie algorytmów znakowania wodnego pod kątem wykorzystania w znakowaniu obrazów medycznych. Porównano algorytmy oparte o całkowitą transformatę falkową (IWT), dyskretną transformatę kosinusową (DCT) i rozkład według wartości osobliwych (SVD). Zaimplementowano algorytmy stosując kombinacje: IWT, IWT-DCT i IWT-SVD. W ramach badań sprawdzono poziom zakłóceń spowodowanych osadzaniem znaku wodnego przy pomocy metod subiektywnych i obiektywnych. Przeprowadzono badania odporności oznakowanych obrazów na ataki i zmierzono pojemność steganograficzną. Wszystkie algorytmy bazują na IWT, jednakże każdy z nich ma inne zalety. Największą pojemność wykazał algorytm oparty o IWT. Najodporniejszy na ataki jest IWT-SVD, a najmniejszy poziom zakłóceń uzyskano dla algorytmu IWT-DCT.

Słowa kluczowe: znakowanie wodne; IWT; DCT; SVD

${ }^{*}$ Corresponding author

Email address: sylwia.duda1@pollub.edu.pl (S. Duda), dominik.fijalek@pollub.edu.pl (D. Fijałek)

CPublished under Creative Common License (CC BY-SA v4.0)

\section{Wstęp}

Zapewnienie ochrony i bezpieczeństwa danych stanowi obecnie jedno z największych wyzwań. Ze względu na swoją wartość, często informacja musi zostać ukryta. Wraz z powstaniem komputerów zaczęto ukrywać informacje w obiektach cyfrowych. W tym celu wykorzystywana jest steganografia [1]. Postępująca cyfryzacja przyczyniła się do powstania cyfrowego znaku wodnego [2], który wywodzi się ze steganografii.

Znakowanie jest także techniką ukrywania informacji, ale istnieje kilka wytycznych, które rozróżniają pojęcie znakowania wodnego od steganografii [3].

Znaki wodne sa stosowane przede wszystkim w celu potwierdzenia autentyczności i praw autorskich. Są stosowane także do wykrywania zmian w oznakowanych plikach. Znakowanie wodne znalazło zastosowanie w wielu dziedzinach, m.in. w medycynie.

W związku z oszustwami dotyczącymi dokumentacji cyfrowy znak wodny jest używany do ukrywania adnotacji medycznych. Pozwala to na potwierdzenie przynależności oraz na wykrycie ewentualnych zmian w oznakowanym dokumencie medycznym.

Obrazy medyczne należą do grupy najbardziej wymagających. W celu ukrycia adnotacji medycznych stosuje się techniki osadzania niewidocznego znaku wodnego, a więc działanie algorytmu nie powinno zniekształcać obrazu ze względu na charakter zdjęć medycznych oraz ważność detali. Oczekując wiernej rekonstrukcji oznakowanego obrazu oraz niezauważalności znaku wodnego, powstają coraz nowsze metody, ale niekoniecznie doskonalsze od istniejących.

W przeciągu ostatnich lat powstało wiele technik znakowania w dziedzinie przestrzennej oraz dziedzinie transformaty. Jednakże ostatnimi czasy popularność zyskały metody oparte o przekształcenie falkowe.

\section{Wybrane algorytmy znakowania wodnego}

\subsection{Metoda ukrywania danych w oparciu o IWT}

Pierwszym z testowanych algorytmów był zaproponowany w artykule pod tytułem "Distortionless data hiding based on integer wavelet transform" przez Guorong Xuan, Jiang Zhu, Jidong Chen, Shi Y.Q., Zhicheng Ni oraz Wei Su [4]. Jest to metoda wykorzystująca do rozkładu obrazu na podpasma całkowitą transformatę falkową. Dane są ukrywane w podpasmach o średniej i wysokiej częstotliwości. Osadzanie odbywa się zgodnie z następującymi krokami:

1. Obraz-nośnik jest wstępnie przetwarzany do całkowitej transformaty falkowej w celu podziału obrazu na podpasma. 
2. Osadzenie znaku wodnego w podpasmach LH, skali szarości obrazów ośmiobitowych.

3. Zastosowanie LL i HL

4. Zastosowanie odwrotnej całkowitej transformaty falkowej w celu uzyskania oznakowanego obrazu.

Algorytm używa IWT w celu uzyskania jak największej pojemności steganograficznej oraz uniknięcia wystąpienia błędu zaokrąglenia, co może wystąpić w przypadku użycia dyskretnej transformaty falkowej.

\subsection{Metoda znakowania wodnego oparta na IWT i DCT}

Kolejna badana metoda wykorzystuje połączenie całkowitej transformaty falkowej (IWT) i dyskretnej transformaty kosinusowej (DCT). Została ona zaproponowana w artykule "Text-image watermarking based on integer wavelet transform" przez Reem A. Alotaibi i Lamiaa A. Elrefaei [5]. Osadzanie znaku wodnego w danych odbywa się według następującego algorytmu:

1. Rozłożenie obrazu nośnika przy pomocy całkowitej transformaty falkowej na cztery podpasma: LL1, LH1, HL1, HH1.

2. Użycie dyskretnej transformaty kosinusowej (DCT) na podpasmie LL1 z podziałem na bloki o rozmiarze $8 \times 8$ pikseli.

3. Wybór współrzędnych w bloku, w których będzie osadzany znak wodny.

4. Dobranie współczynnika skalowalności $\alpha$ zależnego od współrzędnych, na których osadzany zostanie znak wodny.

5. Osadzenie znaku wodnego w wybranych współczynnikach.

6. Użycie odwrotnej dyskretnej transformaty kosinusowej na poszczególnych blokach zmodyfikowanego podpasma LL1.

7. Uzyskanie oznakowanego obrazu poprzez użycie odwrotnej całkowitej transformaty falkowej na wszystkich podpasmach uzyskanych w pierwszym punkcie oraz zmodyfikowanym LL1.

W powyższym procesie osadzania do modyfikacji współczynników DCT został użyty wzór:

$A C^{\prime}{ }_{b, i}=A C_{b, i}+(\alpha * V(i+(b-1) * N))$,

gdzie:

b - numer bloku,

i - numer modyfikowanego współczynnika,

$\mathrm{N}$ - liczba modyfikowanych współczynników w bloku,

$\alpha$ - współczynnik skalowalności,

AC - współczynnik DCT,

V - wektor obrazu znaku wodnego.

\subsection{Metoda znakowania wodnego oparta na IWT i SVD}

Ostatni z badanych algorytmów zakłada wykorzystanie w procesie osadzania znaku wodnego całkowitej transformaty falkowej (IWT) oraz rozkład macierzy na wartości osobliwe (SVD). Metodę zaproponowali P. Gupta i G. Parmar w artykule pod tytułem "Image watermarking using IWT-SVD and its comparative analysis with DWT-SVD" [6]. Spośród dwóch porównywanych w tej pracy algorytmów w badaniach użyto pierwszego z nich. Osadzanie znaku wodnego odbywa się w następujących krokach:

1. Obraz oryginalny i obraz znaku wodnego są rozkładane za pomocą IWT na podpasma LL1, LH1, HL1 oraz HH1.

2. Podpasma LL1 nośnika i znaku wodnego rozkładane są na wartości osobliwe(SVD).

3. Macierz sigma jest obliczana jako fuzja obu macierzy powstałych w wyniku rozkładu na wartości osobliwe.

4. Nowe wartości dla podpasma LL1 są obliczane przy użyciu otrzymanej macierzy sigma oraz odwrotnego rozkładu na wartości osobliwe.

5. Obraz oznakowany jest otrzymywany poprzez użycie odwrotnego IWT na otrzymanym podpasmie LL1 oraz pozostałych z punktu 1.

Aby odzyskać osadzony znak wodny potrzebny jest osadzony znak wodny, obraz oryginalny oraz obraz oznakowany. Wyodrębnianie odbywa się w następujących krokach:

1. Podział obrazu oznakowanego, oryginalnego oraz znaku wodnego na podpasma za pomocą IWT.

2. Użycie SVD do rozkładu na wartości osobliwe obrazów i znaku wodnego.

3. Obliczenie nowej macierzy sigma poprzez zastosowanie fuzji macierzy sigma uzyskanych w kroku nr. 3 oraz współczynnika skalowania.

4. Zastosowanie odwrotnego rozkładu na wartości osobliwe do obliczenia wartości podpasma LL1.

5. Uzyskanie znaku wodnego poprzez zastosowanie odwrotnego IWT na nowo uzyskanym podpasmie LL1 i pozostałych.

\section{Metodyka badawcza}

Jak wspomniano na wstępie, obrazy medyczne należą do jednych z najbardziej wymagających grup obrazów. Ze względu na to, że oznakowane obrazy niekiedy odbiegają w mniejszym lub większym stopniu od oryginału, należy poddać badaniom jakość rekonstruowanych obrazów. Pojęcie obrazu dobrej jakości zależy od kontekstu. W przypadku medycyny jest to nie tylko obraz jasny, ostry i o wysokim kontraście, ale także jest to uzyskanie jak największego podobieństwa obrazu oznakowanego do oryginalnego. W związku z przedmiotem badań jakim są obrazy medyczne, nie istnieją metody, które w jednoznaczny sposób wyłonią jedną technikę znakowania wodnego jako najdoskonalszą spośród badanych. Do oceny oznakowanych zdjęć używane są metody subiektywne i obiektywne. Ze względu na istotność wizualną oraz ważność zachowania detali zdjęć, ocena subiektywna będzie ważniejsza niż obiektywna. Ocena subiektywna to nic innego jak ocena wizualna dokonana ludzkim okiem. Natomiast do obiektywnych zalicza się [7] m.in.:

- MSE - błąd średniokwadratowy,

- SNR - stosunek sygnału do szumu, 
- PSNR - szczytowy stosunek sygnału do szumu,

- SSIM - podobieństwo strukturalne.

Dla poszczególnych metod znakowania wodnego zostały przeprowadzone badania jakości rekonstruowanych obrazów przy pomocy metod obiektywnych. Badania dla każdego z algorytmów zostały przeprowadzone na zbiorze 50 obrazów medycznych o wymiarach $512 \times 512$ pikseli. Natomiast jako znak wodny był używany tekst o długości 104 znaków.

Następnym z przeprowadzonych badań było określenie pojemości steganograficznej, czyli ilości danych jakie mogą zostać ukryte w obrazie o wymiarach $512 \times 512$ pikseli. Badanie polegało na stopniowym zwiększaniu ilości ukrywanych danych w obrazie. Oznakowane obrazy poddawano ocenie jakości oraz sprawdzano czy odzyskany znak wodny jest identyczny z pierwotnym. Dla algorytmu IWT-DWT dodatkowo zwiększano liczbę bitów (w bloku), na których osadzano dane.

Kolejnym $\mathrm{z}$ badań jakie przeprowadzono była analiza odporności na ataki. Oznakowane obrazy modyfikowano za pomocą następujących ataków:

- przesunięcie bitowe,

- rozmycie,

- dodanie szumu,

- usuwanie szumu,

- kompresja JPG,

- korekcja histogramu,

- dostrojenie kontrastu,

- korekcja gamma.

Następnie ze zmodyfikowanego obrazu próbowano wyodrębnić osadzony znak wodny. W badaniu jako znak wodny używany był tekst o długości 104 znaków lub obraz o wymiarach $32 \times 32$ pikseli z umieszczoną na nim informacją. W przypadku udanej próby odzyskania danych ze zmodyfikowanego obrazu dokonywano analizy podobieństwa wyodrębnionego znaku wodnego z oryginalnym. Gdy osadzany był obraz oceniano możliwość przeczytania tekstu umieszczonego na obrazie. Natomiast w przypadku ukrywania tekstu sprawdzana była liczba identycznych znaków.

\section{Wyniki badań}

Wszystkie algorytmy zostały zaimplementowane w środowisku Matlab a następnie przeprowadzone zostały badania. w testach użyto 50 ogólnodostępnych zdjęć medycznych, natomiast do testów odporności na ataki użyto jednego zdjęcia medycznego, zaś znak wodny stanowił tekst oraz obraz.

\subsection{Metoda ukrywania danych w oparciu o IWT}

Na rysunku 1 przedstawiono wykres zależności wartości PSNR od użytej falki. Analizując otrzymane wyniki najlepsze wartości PSNR uzyskano dla falki z rodziny Cohena-Daubechies-Feauveau - cdf2.2. Niewiele gorsze wyniki otrzymano dla falek db1 oraz bior4.4, jednakże wartości PSNR uzyskane dla pierwszej $\mathrm{z}$ nich są bardziej rozproszone. Najmniej zadowalające wartości uzyskano dla falki cdf5.1 i sym6, a dla pierwszej z nich uzyskano wiele wyników odstających. Rozbieżność wyników oscyluje w granicach $28-38,5 \mathrm{~dB}$.

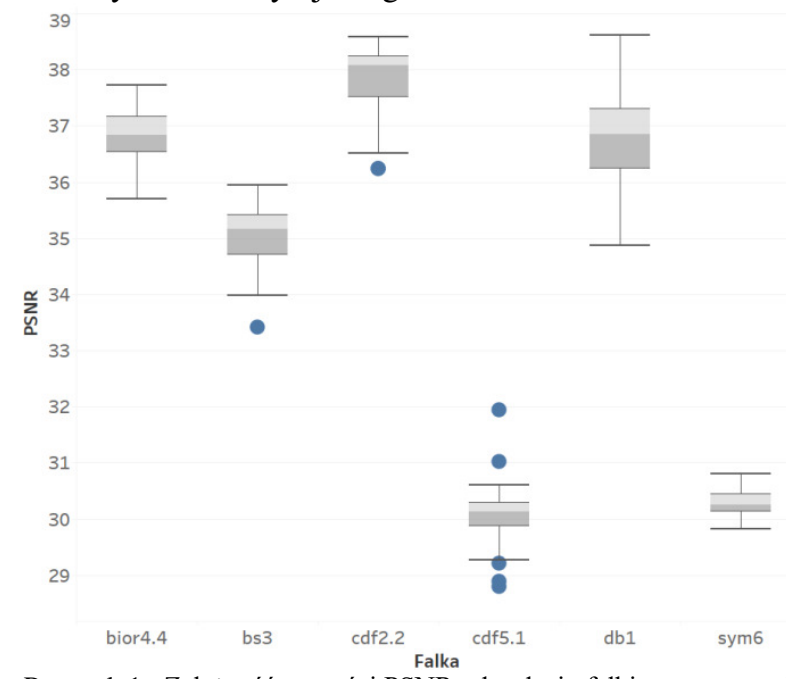

Rysunek 1: Zależność wartości PSNR od rodzaju falki zastosowanej $\mathrm{w}$ algorytmie opartym o IWT

\subsection{Metoda znakowania wodnego oparta na IWT i DCT}

Na rysunku 2 przedstawiono wykres zależności wartości PSNR od użytej falki w całkowitej transformacie falkowej dla algorytmu opartego o IWT-DCT. Wyniki badań pokazują, że ponownie najlepsze wartości PSNR uzyskano dla falek cdf2.2 (32-62 dB) i db1 (31-61 dB). Natomiast rozstęp ćwiartkowy dla falki cdf2.2 jest mniejszy niż w przypadku falki db1. Pozostałe wyniki są znacznie niższe, a najgorzej wypadła falka sym6 uzyskując wartości PSNR w zakresie 14-16 dB. Natomiast falka bior4.4 w przypadku tego algorytmu uzyskała wyniki porównywalne $\mathrm{z}$ falkami bs3 oraz cdf5.1.

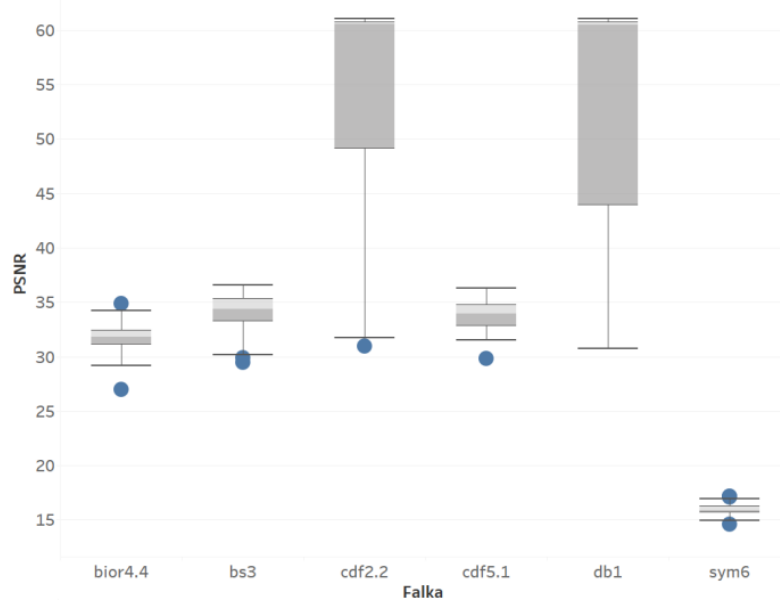

Rysunek 2: Zależność wartości PSNR od rodzaju falki zastosowanej w algorytmie opartym o IWT-DCT

\subsection{Metoda znakowania wodnego oparta na IWT i SVD}

Na rysunku 3 przedstawiono wykres zależności wartości PSNR od użytej falki dla algorytmu opartego o IWTSVD. Najlepsze wyniki PSNR uzyskano dla falki bior4.4-45,5-47 dB. Następnie najlepsze wyniki otrzymano dla falek db1 - około $43 \mathrm{~dB}$ oraz cdf2.2 około $42 \mathrm{~dB}$. Zdecydowanie najgorsze wartości oscylu- 
jące w zakresie 6,19-10,84 dB uzyskano dla falki cdf5.1 Algorytm IWT-SVD charakteryzuje się małym rozproszeniem wyników w obrębie danej falki.

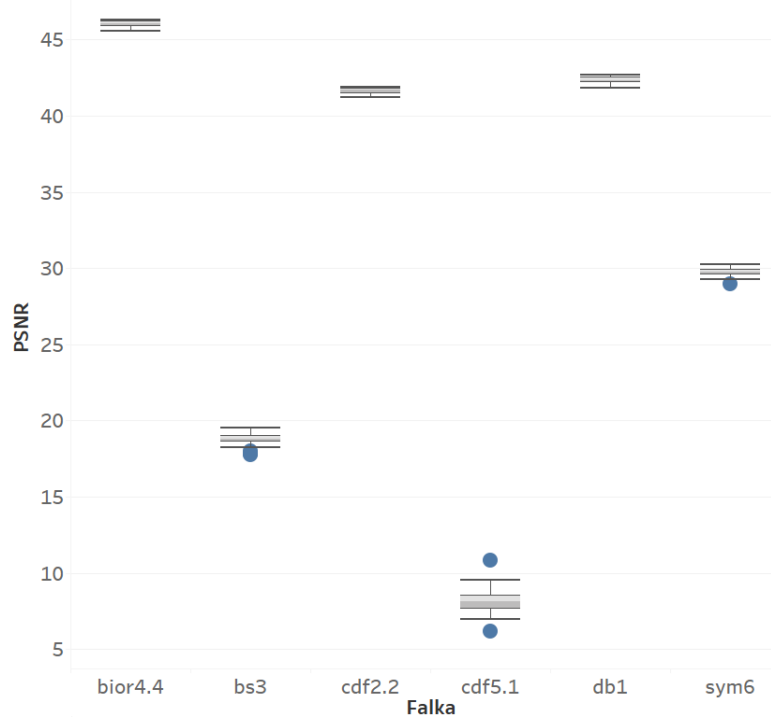

Rysunek 3: Zależność wartości PSNR od rodzaju falki zastosowanej w algorytmie opartym o IWT-SVD

\subsection{Porównanie metod}

Zestawienie otrzymanych średnich wartości dla miar obiektywnych zostało przedstawiony w tabeli 1 . Biorąc pod uwagę wyniki otrzymane dla miary sprawdzającej stosunek sygnału do szumu (PSNR) najlepsze wyniki uzyskano dla algorytmu wykorzystującego IWTDCT(im wyższa wartość tym lepsza jakość). Pozostałe algorytmy uzyskały wartości średnie gorsze o ponad $10 \mathrm{~dB}$, natomiast nieco lepiej wypadła w tym przypadku metoda oparta o IWT-SVD. Najgorsze wartości średnie miar PSNR oraz SNR otrzymano dla metody IWT. Wyniki średnie uzyskane dla miar MSE oraz SSIM otrzymane dla metody ukrywania danych opartej o IWT odbiegają znacznie od pozostałych algorytmów (im niższa wartość tym lepsza jakość), natomiast w przypadku pozostałych metod ukrywania danych wartości te są bardzo do siebie zbliżone.

Tabela 1: Porównanie wartości PSNR, SNR, MSE oraz SSIM dla poszczególnych algorytmów

\begin{tabular}{|l|c|l|l|l|}
\hline Algorytm & $\begin{array}{c}\text { SNR } \\
{[\mathbf{d B}]}\end{array}$ & $\begin{array}{c}\text { PSNR } \\
{[\mathbf{d B}]}\end{array}$ & MSE & SSIM \\
\hline IWT & 32,27 & 37,86 & 10,36 & 0,9217 \\
\hline IWT-DCT & 48,72 & 54,32 & 4 & 0,9991 \\
\hline IWT-SVD & 36,18 & 41,64 & 4 & 0,9981 \\
\hline
\end{tabular}

Wyniki badań pojemności steganograficznej przedstawione w tabeli 2 wskazują, że najwięcej danych można ukryć przy pomocy algorytmu opartego o IWT, natomiast algorytm wykorzystujący IWT-DCT pozwala na ukrycie jedynie 1024 bitów danych, taki wynik jest efektem ukrywania danych jedynie w jednym bicie podpasma LL1 przekształconego za pomocą DCT.
Tabela 2: Zestawienie wartości pojemności steganograficznej

\begin{tabular}{|l|l|}
\hline Algorytm & Pojemność steganograficzna [b] \\
\hline IWT & 195000 \\
\hline IWT-DCT & 1024 \\
\hline IWT-SVD & 16384 \\
\hline
\end{tabular}

Tabela 3 przedstawia wyniki badań związanych $\mathrm{z}$ atakami mającymi na celu uniemożliwienie odzyskania znaku wodnego, wykazały one brak odporności algorytmu opartego o IWT-DCT na wszystkie przeprowadzone ataki. Największą odporność uzyskano dla algorytmu wykorzystującego IWT-SVD, gdzie dane udało się odzyskać po przeprowadzeniu pięciu z dziewięciu ataków. w przypadku algorytmu opartego o IWT odporność wykazano w przypadku trzech prób usunięcia znaku wodnego, natomiast tylko w jednym przypadku algorytm pozwolił odzyskać w pełni czytelny znak wodny.

Tabela 3: Wyniki badań odporności na ataki dla poszczególnych algorytmów

\begin{tabular}{|l|c|c|c|}
\hline \multicolumn{1}{|c|}{ Typ ataku } & IWT & $\begin{array}{c}\text { IWT- } \\
\text { DCT }\end{array}$ & $\begin{array}{c}\text { IWT- } \\
\text { SVD }\end{array}$ \\
\hline $\begin{array}{l}\text { Przesunięcie } \\
\text { bitowe }\end{array}$ & Brak & Brak & Duża \\
\hline Obrót & Brak & Brak & Brak \\
\hline Rozmycie & Brak & Brak & Duża \\
\hline $\begin{array}{l}\text { Dodanie } \\
\text { szumu }\end{array}$ & Brak & Brak & Brak \\
\hline $\begin{array}{l}\text { Usuwanie } \\
\text { szumu }\end{array}$ & Brak & Brak & Brak \\
\hline $\begin{array}{l}\text { Kompresja } \\
\text { JPG }\end{array}$ & Brak & Brak & Brak \\
\hline $\begin{array}{l}\text { Korekcja } \\
\text { histogramu }\end{array}$ & Średnia & Brak & Średnia \\
\hline $\begin{array}{l}\text { Dostrojenie } \\
\text { kontrastu }\end{array}$ & Duża & Brak & Średnia \\
\hline $\begin{array}{l}\text { Korekcja } \\
\text { gamma }\end{array}$ & Niska & Brak & Duża \\
\hline
\end{tabular}

\section{Wnioski}

Celem badań było wyłonienie algorytmu znakowania wodnego, który będzie najodpowiedniejszy dla znakowania obrazów medycznych. Na podstawie przeprowadzonych badań nie można wyłonić algorytmu, który byłby najdoskonalszym spośród badanych.

Metoda ukrywania danych w oparciu o IWT charakteryzuje się największą pojemnością steganograficzną, co umożliwi osadzanie dosyć obszernych adnotacji medycznych. Warto jednak mieć na uwadze, że im większa ilość osadzonych danych tym niższa jakość rekonstruowanego obrazu a ta metoda uzyskała najmniejsze wartości miar obiektywnych spośród badanych technik znakowania.

Metoda znakowania wodnego oparta na IWT i DCT charakteryzuje się dosyć małą pojemnością steganograficzną w porównaniu do pozostałych badanych algorytmów oraz brakiem odporności. Definitywny brak odporności na ataki sprawia, że nie ma możliwości odtworzenia osadzonego znaku. Jedyną zaletą jest osadzenie 
niewielkiej ilości adnotacji medycznych przy jednoczesnym zachowaniu bardzo dużego podobieństwa obrazu oznakowanego do oryginalnego.

Metoda znakowania wodnego oparta na IWT i SVD uzyskała najlepsze wyniki pod względem badań odporności na ataki. Algorytm cechuje się również dobrą jakością oznakowanego obrazu jak i wystarczająca pojemnością steganograficzną.

Zaobserwowano, że połączenie metody IWT z DCT czy SVD wpływa na zmniejszenie pojemności steganograficznej, jednakże połączenie metod zapewnia nowe właściwości, takie jak zwiększenie jakości rekonstruowanego obrazu lub odporności na ataki. Natomiast nie istnieje algorytm, który jednocześnie charakteryzowałby się dużą pojemnością steganograficzną, dobrej jakości zrekonstruowanym obrazem i odpornością na ataki.

\section{Literatura}

[1] G. Kozieł, Zmodyfikowane metody cyfrowego przetwarzania sygnałów dźwiękowych w steganografii komputerowej, Politechnika Lubelska, Lublin 2010.
[2] D. Bogumił, Cyfrowe znaki wodne odporne na kompresję JPEG, Politechnika Warszawska, Instytut Informatyki, wrzesień 2001.

[3] Różnice między steganografią a znakowaniem wodnym, https://absta.pl/zakad-ochrony-informacji.html?page=8, [02.10.2020].

[4] G. Xuan, J. Chen, J. Zhu, Y.Q. Shi, Z. Ni, W. Su, Lossless data hiding based on integer wavelet transform, 10.1109/MMSP.2002.1203308 (2003) 312-315.

[5] A.R. Alotaibi, A.L. Elrefaei: Text-image watermarking based on integer wavelet transform (IWT) and discrete cosine transform (DCT), Applied Computing and Informatics, 2019.

[6] P. Gupta, G. Parmar, Image watermarking using IWTSVD and its comparative analysis with DWT-SVD, 10.1109/COMPTELIX.2017.8004026 (2017) 527-561.

[7] A. Horé, D. Ziou, Image quality metrics: PSNR vs. SSIM. 10.1109/ICPR.2010.579 (2010) 23662369. 